\title{
The assessment of heavy metal distribution in the sediment of eastern Chongming tidal flat, China
}

\author{
J. Lu \& F. Yuan \\ Department of Engineering and Safety, University of Tromsø, Norway
}

\begin{abstract}
The distribution of heavy metals in tidal flat sediment is of great significance on the estuary environment. This study aims to find the heavy metal distribution mechanism at different parts of the tidal flat on the Yangtze Estuary, China. Eleven sediment cores were collected at the high, middle and low tidal flats of eastern Chongming Island in four seasons - spring, summer, autumn and winter. The contents of elements $\mathrm{Al}, \mathrm{Cu}, \mathrm{Cr}, \mathrm{Fe}, \mathrm{Mn}, \mathrm{Pb}, \mathrm{Rb}, \mathrm{S}, \mathrm{Si}, \mathrm{Sr}, \mathrm{Zn}, \mathrm{Zr}$ and humic acid in the sediment were analyzed. Pearson correlation analysis and principle component analysis (PCA) were used to analyze the main factors for heavy metal distribution in the tidal flat. The results showed that the redox and $\mathrm{pH}$ conditions in the sedimentation environment, grain size and humic acid had a significant effect on the distribution of heavy metals in the sediment of the tidal flat. The leading factors for heavy metal distribution and migration in the sediments are different at different parts of the tidal flat. The main factors for heavy metal distribution in the sediment of the low tidal flat are the source of sediment and the hydrodynamic force, while in the middle and high tidal flats, the effect of humic acid increases. The heavy metal distribution in the sediments of the middle tidal flat is mainly affected by the redox and $\mathrm{pH}$ condition of the sedimentation environment and humic acid, while in the high tidal flat, humic acid is the main controlling factor for heavy metal distribution in the sediment.

Keywords: heavy metal, sediment, tidal flat, particle size, humic acid, redox cycle, $p H$.
\end{abstract}




\section{Introduction}

Estuary areas are important feeding grounds for migrant and native birds as well as a nursery zone for fish [1]. They are highly vulnerable to the pollutant inputs from river and adjacent areas [2]. Heavy metal pollution in the estuary environment is a critical problem and poses a serious ecological risk to the coastalmarine ecosystems due to the high toxicity, persistence and non-degradable nature of heavy metals [3]. The sediment in the estuary area plays an essential environmental role to receive and release heavy metals to and from the adjacent area [3]. Sediment pollution by heavy metals has been regarded as a critical problem in marine environment because of their toxicity, persistence and bioaccumulation $[4,5]$. The accumulation of heavy metals in sediments will significantly influence the health of the marine ecosystems $[4,5]$. Therefore, the study on heavy metal distribution in the estuarine sediment is of great significance.

The Yangtze River is the largest river in China and the fourth largest in the world with respect to sediment flux (ca. $4.86 \times 10^{8}$ tons/year), of which approximately half of the river-derived sediment is deposited in its estuary $[6,7]$. Eastern Chongming tidal flat is a well-developed tidal flat and the largest intertidal zone of the Yangtze River estuary. The sediment of the tidal flat is highly affected by the municipal and industrial sewage discharge from Shanghai, most part of which is untreated [8]. Therefore, the study on the heavy metal distribution in the sediment of eastern Chongming tidal flat is of great importance.
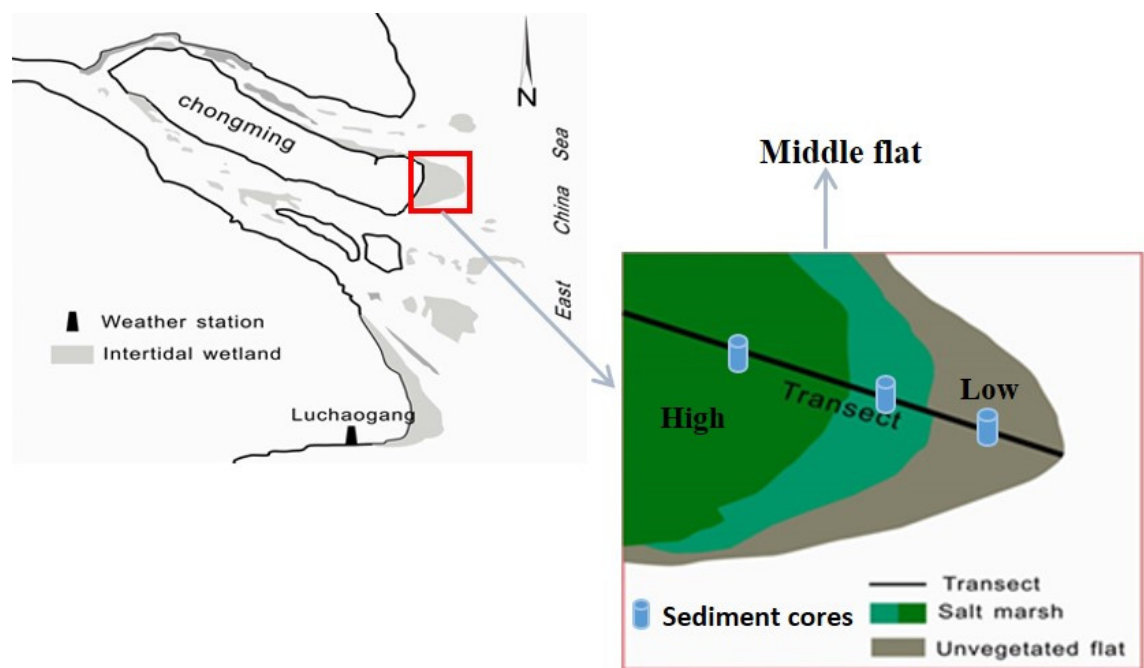

Figure 1: Study area and sampling points.

The heavy metal distribution in the sediment of the tidal flat is affected by many factors, such as grain size [9-11], redox cycle of Fe and Mn, humic acid [7], anthropogenic and lithogenic sources [3], the textual characteristic, mineralogical composition and depositional environment [11]. Although there have been 
extensive studies on the heavy metal distribution in the tidal flat sediment, the systematic investigation on the heavy metal distribution at each part of the tidal flat is scare. In the current study, the heavy metal distribution mechanism at different parts of eastern Chongming tidal flat, i.e. from the high to middle and low tidal flat, was analyzed and discussed extensively.

\section{Materials and methods}

\subsection{Sampling and pretreatment}

This study selects the eastern Chongming tidal flat as the study area. The natural geomorphic and sediment zonation of the flat is obvious, which can be divided into high, middle and low tidal flat from land to sea. As the tidal flat is well developed, we collect the sediment core samples at three different places of the tidal flat: high, middle and low. The sampling was conducted in a year at four different seasons: spring, summer, autumn and winter on the transect line of the tidal flat (Figure 1). At high tidal flat, the sediment cores were collected at three seasons: spring, summer and winter. Totally 11 sediment cores were collected.

The sediment cores were collected with PVC pipe (ca. $40 \mathrm{~cm}$ in length, $10 \mathrm{~cm}$ in diameter) at high, middle and low tidal flat during ebbing period. All cores were plugged and sealed with tape immediately at site and taken to the lab. In the lab, the sediment cores were divided into subsamples at $2 \mathrm{~cm}$ intervals with knife under room conditions. Each subsample was immediately put into a plastic bag, and sealed after squeezing out the air as much as possible. It was then stored in the refrigerator at $4{ }^{\circ} \mathrm{C}$ until analysis. Before analysis, the samples were air-dried at room temperature, grounded with a pestle and mortar until all particles passed through a 240-mesh nylon sieve.

\subsection{Total humic acid analysis}

Humic acid was tested according to GB-7858-87 standard method and the gravimetric California Department of Food (CDFA) method [12]. The detailed description of the method was described in our recent publication in 2016 [7].

\subsection{Major and trace element analysis}

$4 \mathrm{~g}$ sediment sample was weighed and put onto a low pressure polyethylene base. The sample was then pressed at $37.5 \mathrm{t}$ pressure to a circular ring with an inner diameter of $31 \mathrm{~mm}$ and an outer diameter of $40 \mathrm{~mm}$. The content of major and trace element $\mathrm{Al}, \mathrm{Cu}, \mathrm{Cr}, \mathrm{Fe}, \mathrm{Mn}, \mathrm{Pb}, \mathrm{Rb}, \mathrm{S}, \mathrm{Sr}, \mathrm{Zn}, \mathrm{Zr}$ were analyzed by X-ray fluorescence spectrometry (XRF 1800, Shimadzu, Japan). China Stream Sediment standard Reference Material GSD-9 was tested simultaneously with each set of samples to evaluate the accuracy of the test. The recoveries for element $\mathrm{Al}, \mathrm{Cu}$, $\mathrm{Fe}, \mathrm{Pb}, \mathrm{Rb}, \mathrm{Sr}, \mathrm{Zn}$ and $\mathrm{Zr}$ ranged from $91 \%$ to $103 \%$ compared with the certified values and the analytical precision was within 15\%. The recoveries for elements $\mathrm{Mn}, \mathrm{Cr}$ and $\mathrm{S}$ are $120 \%, 79 \%$ and $65 \%$ respectively. 


\subsection{Statistical analysis}

In this study, Pearson correlation analysis and principle component analysis (PCA) were conducted with SPSS 12.0.

\section{Results and discussions}

\subsection{The results of correlation and principle component analysis (PCA)}

Pearson correlation analysis and principal component analysis (PCA) were performed on all the analyzed elements and humic acid. All the data was standardized before the principal component analysis. The results are shown in Tables 1 and 2. Two principal components were extracted.

\subsubsection{The explanation of the first principal component}

The first principal component can explain $87 \%$ of the total variance. $\mathrm{Al}, \mathrm{Cu}, \mathrm{Fe}$, $\mathrm{Mn}, \mathrm{Rb}, \mathrm{S}$ and $\mathrm{Zn}$ all have high positive load on the first component. The load of them is in the range of 0.74-0.96, among which $S$ has the highest load of 0.96, whereas $\mathrm{Si}$ and $\mathrm{Sr}$ have a relative high negative load of -0.75 and -0.76 on the first component.

Table 1: The results of principal component analysis.

\begin{tabular}{ccc}
\hline Factors & \multicolumn{2}{c}{ Principal component } \\
\hline $\mathrm{Sr}$ & -0.76 & -0.64 \\
$\mathrm{Rb}$ & 0.79 & 0.60 \\
$\mathrm{Cu}$ & 0.74 & 0.66 \\
$\mathrm{~S}$ & 0.96 & 0.03 \\
$\mathrm{Zr}$ & -0.48 & -0.78 \\
$\mathrm{Mn}$ & 0.74 & 0.65 \\
$\mathrm{Cr}$ & -0.50 & -0.78 \\
$\mathrm{~Pb}$ & 0.54 & 0.79 \\
$\mathrm{Si}$ & -0.75 & -0.64 \\
$\mathrm{Fe}$ & 0.84 & 0.52 \\
$\mathrm{Zn}$ & 0.79 & 0.60 \\
$\mathrm{Al}$ & 0.90 & 0.42 \\
$\mathrm{Humic}$ acid & 0.08 & 0.97 \\
\hline
\end{tabular}




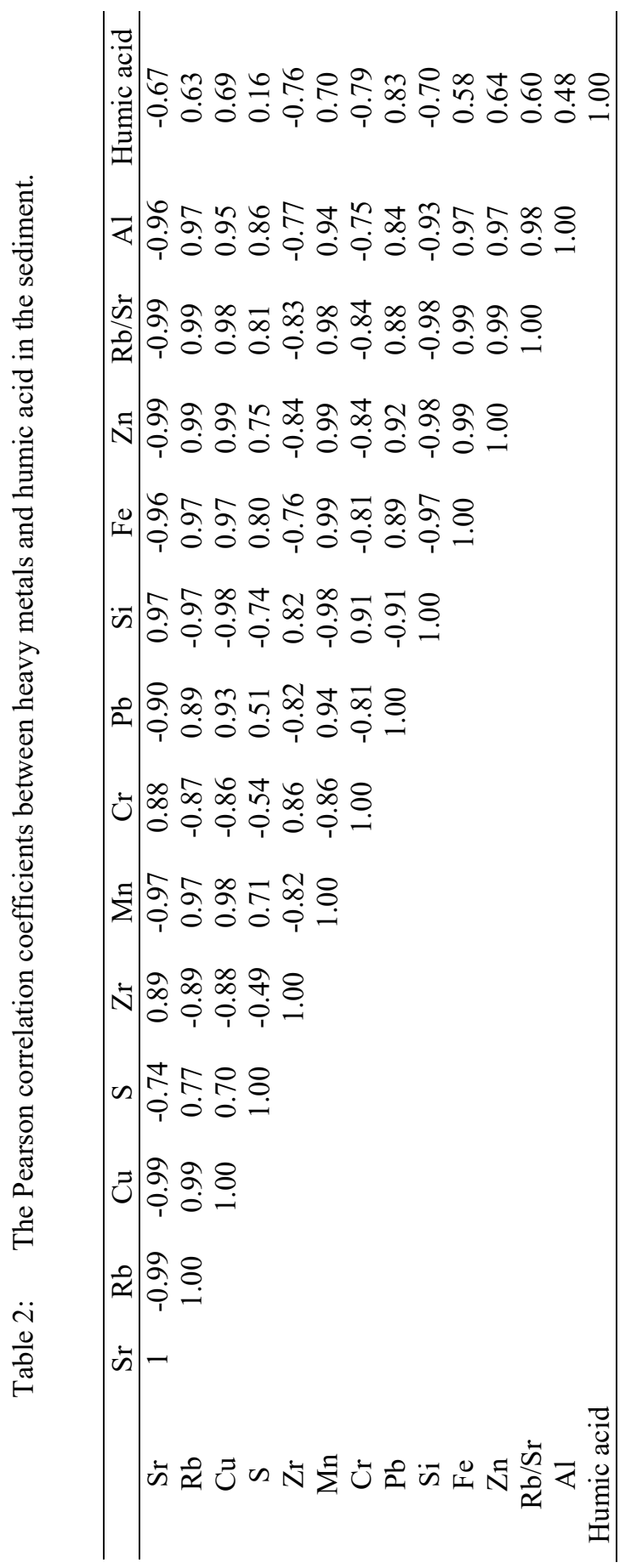


Tidal flat sediments are periodically inundated by saline water which enters the sediment system during high tides and slowly leached out from ground water at low tide [13]. Periodical waterlogging of tidal flat sediments restricts atmospheric oxygen diffusion into the sediments, which can promote the development of anoxic sediment conditions [13]. When the organic decomposes in the anoxic environment, $\mathrm{NO}_{3}{ }^{-}, \mathrm{Mn}^{4+}, \mathrm{Fe}^{3+}, \mathrm{SO}_{4}{ }^{2-}$ all can join the cycling of carbon as electron acceptor [14]. In marine sedimentation environment, the geochemistry of $\mathrm{C}, \mathrm{Fe}$ and $S$ is closely related with each other [15-17]. Driven by organic matter decomposition, hydrogen sulfide from sulfate reduction can reduce high valent oxidative iron to reductive state and form iron sulfide [18], thus affect the distribution of other heavy metals in the sediment. Heavy metals in the Yangtze River Estuary mainly migrate together with clay minerals, clayey-sized particles and suspended organic particles, and accumulate in the tidal flat under certain hydrodynamic conditions. The high positive load of Fe, Mn and S in the first principle component can be understood as that the distribution of heavy metals is controlled by the geochemistry cycle of $\mathrm{Fe}, \mathrm{Mn}$ and $\mathrm{S}$ to a certain extent during early diagenesis. Due to the drastic changes in redox conditions during the early diagenesis in the sediment, many heavy metals will remigrate together with redoxsensitive elements Fe and Mn after deposition, and enrich at the redox boundary layer together with $\mathrm{Fe}$ and $\mathrm{Mn}$. The sulfate reduction leads to the formation of metal sulphides. Therefore, the redox condition is one of the most important factors for heavy metal migration and transformation in the sediment.

$\mathrm{Al}, \mathrm{Cu}, \mathrm{Fe}, \mathrm{Mn}, \mathrm{Rb}$ and $\mathrm{Zn}$ have relatively high positive load on the first principal component, and the correlation coefficients between them are high, which reflects the impact of particle size on the migration and transformation of heavy metals. Heavy metals have a strong ability to be absorbed by clay minerals, and $\mathrm{Al}$ is the main chemical component of clay minerals. The sediments with high content of clay minerals usually results in low redox potential environment, which will reduce the oxygen exchange capacity significantly than course-grained sediments. This will make the reduction of Fe, Mn and sulfate salts easier, and thus produce more sulphides than in the course-grained sediment, which can promote the fixation of metal ions in the sediment.

The high negative load of $\mathrm{Sr}$ on the first principal component is related with the change of $\mathrm{pH}$ in the environment. Sr is a typical dispersed element and mainly exists in isomorphic form in all types of rock-forming minerals. Sr rarely exist as independent minerals. Sr and $\mathrm{Ca}$ have similar geochemical parameters such as particle radius, electric potential. Therefore, Sr normally exist in the Ca containing minerals in isomorphic form, including $\mathrm{Ca}$ silicates (plagioclase, amphibole, pyroxene, etc.) and Ca carbonates. During the weathering process, carbonates containing $\mathrm{Ca}$ and $\mathrm{Sr}$ will decompose after weathering, and therefore $\mathrm{Sr}$ will go into solution as ion form together with $\mathrm{Ca}$ ion. $\mathrm{Si}$ in the sediment is mainly from the hydrolysis of silicate minerals, and present as course quartz particles. Phase analysis in the Yangtze River estuary showed that the suspended solids and sediments contain more than $40 \%$ of quartz [19]. Therefore, the transportation of $\mathrm{Sr}$, $\mathrm{Si}$ in the supergene geochemical process is mainly affected by the $\mathrm{pH}$ condition of the environment. 
In summary, the first principal component can be interpreted as the effect of redox conditions, $\mathrm{pH}$ and grain size composition of the sediment.

\subsubsection{The explanation of the second principal component}

Humic acid has a high positive load on the second principal component, which can explain $8.3 \%$ of the total variance. Humic acid can promote the migration of heavy metals in the environment due to their specific functional groups. Some heavy metals can bond to the functional groups in humic acid directly, and migrate together with humic acid. Humic acid itself also has a strong reducing ability and colloidal properties. Many elements have high solubility in their lower valence state and humic acid can reduce them from high valence state to low valence state. Thus heavy metals can migrate together with humic acid and maintain the stability of valence during the migration process due to the specific functional groups in the humic acid.

$\mathrm{Cr}$, Si and $\mathrm{Zr}$ have high negative load on the second principal component, which indicates the effect of sediment source on the distribution of heavy metals. $\mathrm{Zr}$ is mainly produced and concentrated in the heavy minerals, and is normally found in relatively coarse siliciclastic particles in the sediment [20]. For the sediments with the same source, the content of $\mathrm{Zr}$ can be used to indicate the content of the relatively course sandy silicate minerals [21]. Studies have found that $\mathrm{Cr}$ in the environment mainly migrated with relatively course particles in the sediment [22]. It was found that the content of $\mathrm{Cr}$ in the sediment is related with the content of silt with a correlation coefficient of 0.45 at 0.01 level, whereas there is no relationship between the content of $\mathrm{Cr}$ and the clay content in the sediment [23]. The high negative load of $\mathrm{Cr}$ and $\mathrm{Zr}$ on the second principal component confirms that the heavy metals bonded with humic acid are mainly adsorbed to the fine particles, and deposit in the tidal flat under appropriate hydrodynamic conditions. Results from correlation analysis showed that $\mathrm{Cr}$ and $\mathrm{Zr}$ had a negative correlation with $\mathrm{Fe}$ and $\mathrm{Mn}$, which indicates that the content of $\mathrm{Cr}$ and $\mathrm{Zr}$ in the sediment is not affected by the geochemical cycle of $\mathrm{Fe}$ and $\mathrm{Mn}$. Therefore, the second principal component can be illustrated as the effect of humic acid.

\subsection{The analysis on each part of the tidal flat}

The average score on the first and second principal component for each sediment core was calculated and shown in Figure 2. The main factors for heavy metal distribution in the sediment are different at different parts of the tidal flat (high, middle and low tidal flat). The average scores on the two components for the four sediment cores from low tidal flat are low. This illustrates that the heavy metal distribution in the sediment of low tidal flat is not obviously affected by the two principal components since the low tidal flat has been in a constant state of agitation and the mixing of sediment is strong. The main factor for heavy metal distribution in the sediment of low tidal flat is sediment source and the hydrodynamic force. The high tidal flats have the highest average score on the second principal component, which indicates that the heavy metal distribution in the sediments of the high tidal flat is mainly affected by the humic acid. The 
middle tidal flats have a relatively high average score on the first principal component, which showed that the distribution of heavy metals in the sediments of middle tidal flat was strongly affected by the redox and $\mathrm{pH}$ conditions of the sedimentation environment, but also affected by the humic acid to a certain extent.

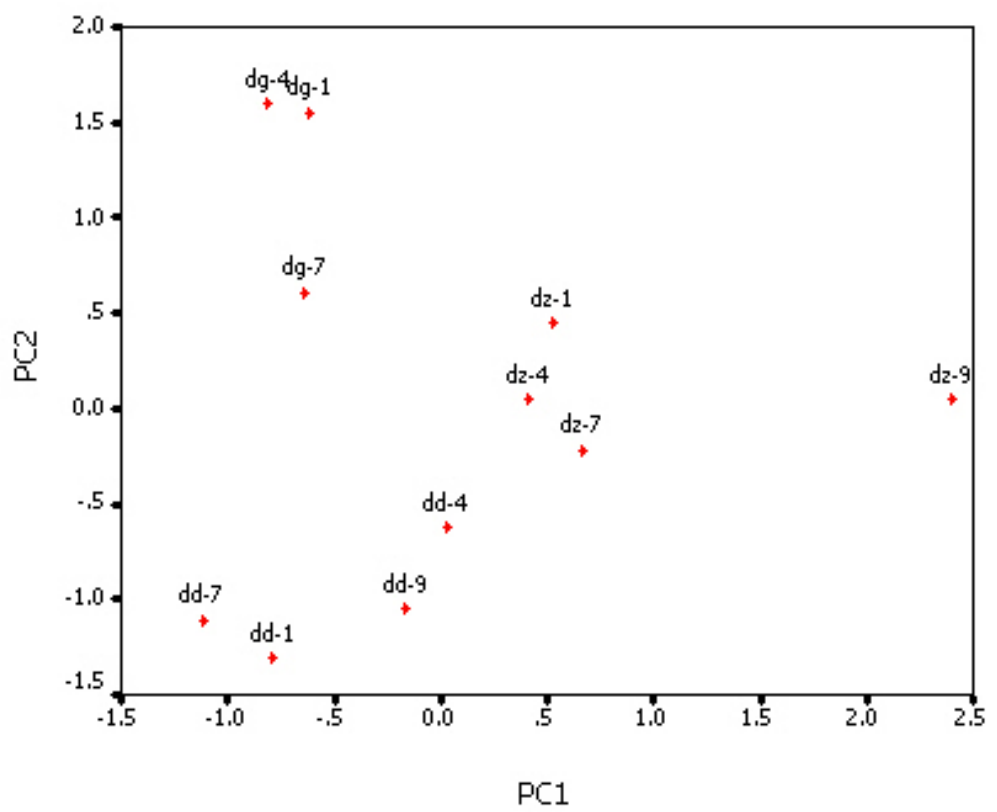

Figure 2: Average score on the principal components for sediment cores. (PC1 and $\mathrm{PC} 2$ denote the first principal component and the second principal component respectively; dg-1, dg-4, dg-7 denote the high tidal flat in winter, spring and summer respectively; dz-1, dz-4, dz-7 and dz-9 denote the middle tidal flat in winter, spring, summer and autumn respectively; dd-1, dd-4, dd-7 and dd-9 denote the low tidal flat in winter, spring, summer and autumn respectively.)

\section{Conclusions}

The heavy metal distribution in the sediments of eastern Chongming tidal flat is dominated by different factors at different parts of the tidal flat. The main factors for heavy metal distribution in the sediment of low tidal flat are grain size, the source of sediment and the hydrodynamic force. The distribution of heavy metals in the sediments of middle tidal flat is strongly affected by the redox and $\mathrm{pH}$ conditions of the sedimentation environment, but also affected by the humic acid to a certain extent. While in the high tidal flat, the distribution of heavy metals in the sediments is dominated by humic acid. The heavy metal contamination has a significant effect on the health of the vulnerable ecosystems living in this region. 
A further study on how these factors affect the transportation and fate of heavy metals in the estuary area is necessary.

\section{References}

[1] S. E. Botte, R. H. Freije, and J. E. Marcovecchio, "Distribution of Several Heavy Metals in Tidal Flats Sediments within Bahia Blanca Estuary (Argentina)," Water Air and Soil Pollution, vol. 210, pp. 371-388, Jul 2010.

[2] X. J. C. Gao, Z.L.; Zhang, N.L.; Xu, S.Y.; Chen, L.M., "Heavy metals and phosphorus in tidal flat sediments of the Yangtze estuary " Journal of Geographical Sciences, vol. 12, pp. 472-478, 2002.

[3] H. J. Pang, Z. H. Lou, A. M. Jin, K. K. Yan, Y. Jiang, X. H. Yang, et al., "Contamination, distribution, and sources of heavy metals in the sediments of Andong tidal flat, Hangzhou bay, China," Continental Shelf Research, vol. 110, pp. 72-84, Nov 12015.

[4] R. Zhang, L. Zhou, F. Zhang, Y. J. Ding, J. R. Gao, J. Chen, et al., "Heavy metal pollution and assessment in the tidal flat sediments of Haizhou Bay, China," Marine Pollution Bulletin, vol. 74, pp. 403-412, Sep 152013.

[5] W. F. Zhang, X. P. Liu, H. F. Cheng, E. Y. Zeng, and Y. A. Hu, "Heavy metal pollution in sediments of a typical mariculture zone in South China," Marine Pollution Bulletin, vol. 64, pp. 712-720, Apr 2012.

[6] S. Lin, I. J. Hsieh, K.-M. Huang, and C.-H. Wang, "Influence of the Yangtze River and grain size on the spatial variations of heavy metals and organic carbon in the East China Sea continental shelf sediments," Chemical Geology, vol. 182, p. 377, 2/15 2002.

[7] J. Y. Lu, F.; Zhang, F.; Zhao, Q., "The study on heavy metal distribution in the sediment of middle tidal flat in Yangtze Estuary, China," Environmental Earth Sciences, vol. 75, p. 557, 2016.

[8] Z. L. Chen, P. F. Liu, S. J. Xu, L. Liu, J. Yu, and L. Z. Yu, "Spatial distribution and accumulation of heavy metals in tidal flat sediments of Shanghai coastal zone," Science in China Series B-Chemistry, vol. 44, pp. 197-208, Aug 2001.

[9] T. K. K. Kim, E. S.; Cho, S. R.; Park, J. K.; Ra, K. T.; Lee, J. M., "Distribution of Heavy Metals in the Environmental Samples of the Saemangeum Coastal Area, Korea," Coastal Environmental and Ecosystem Issues of the East China Sea, pp. 71-90, 2010.

[10] J. Y. Huang, Y.; Xu, J.; Zhu, X. "Spatial distribution features and environment effect of heavy metal in intertidal surface sediments of Guanhe estuary, Northern Jiangsu Province," Frontiers of Earth Science in China, vol. 2, pp. 147-156, 2008.

[11] A. Parizanganeh, "Grain size effect on trace metals in contaminated sediments along the Iranian coast of the Caspian sea," 2008, p. 329.

[12] H. Kerndorff and M. Schnitzer, "Sorption of metals on humic acid," Geochimica et Cosmochimica Acta, vol. 44, p. 1701, 111980. 
[13] T. P. Williams, J. M. Bubb, and J. N. Lester, "Metal Accumulation within Salt-Marsh Environments - a Review," Marine Pollution Bulletin, vol. 28, pp. 277-290, May 1994.

[14] D. J. Burdige, "The Biogeochemistry of Manganese and Iron Reduction in Marine-Sediments," Earth-Science Reviews, vol. 35, pp. 249-284, Oct 1993.

[15] S. E. Calvert and R. E. Karlin, "Relationships between Sulfur, OrganicCarbon, and Iron in the Modern Sediments of the Black-Sea," Geochimica Et Cosmochimica Acta, vol. 55, pp. 2483-2490, Sep 1991.

[16] R. G. Gerritse, P. J. Wallbrink, and A. S. Murray, "Accumulation of phosphorus and heavy metals in the Swan-Canning Estuary, Western Australia," Estuarine Coastal and Shelf Science, vol. 47, pp. 165-179, Aug 1998.

[17] R. A. Chambers, J. W. Fourqurean, S. A. Macko, and R. Hoppenot, "Biogeochemical effects of iron availability on primary producers in a shallow marine carbonate environment," Limnology and Oceanography, vol. 46, pp. 1278-1286, Sep 2001.

[18] D. E. Canfield and R. A. Berner, "Dissolution and Pyritization of Magnetite in Anoxic Marine-Sediments," Geochimica Et Cosmochimica Acta, vol. 51, pp. 645-659, Mar 1987.

[19] Q. M. C. Chen, Y.Q.; Chen, B.L.; Chen, J.Y., "The phase analysis on the suspended solids and sediments in the Yangtze River estuary (in Chinese)," Journal of East China Normal University (Natural Science), pp. 77-83, 2001.

[20] P. W. Fralick and B. I. Kronberg, "Geochemical discrimination of elastic sedimentary rock sources," Sedimentary Geology, vol. 113, pp. 111-124, Oct 1997.

[21] H. Dypvik and N. B. Harris, "Geochemical facies analysis of fine-grained siliciclastics using $\mathrm{Th} / \mathrm{U}, \mathrm{Zr} / \mathrm{Rb}$ and ( $\mathrm{Zr}$ plus $\mathrm{Rb}$ )/Sr ratios," Chemical Geology, vol. 181, pp. 131-146, Oct 152001.

[22] C. J. Bi, "Environmental biogeochemistry of Heavy Metals in Intertidal Flat of the Yangtze Estuary (in Chinese)," PhD, East China Normal University, Shanghai, China, 2004.

[23] M. F. Soto-Jimenez and F. Paez-Osuna, "Distribution and normalization of heavy metal concentrations in mangrove and lagoonal sediments from Mazatlan Harbor (SE Gulf of California)," Estuarine Coastal and Shelf Science, vol. 53, pp. 259-274, Sep 2001. 